\title{
Research on the Behavior Evaluation for Social Responsibility of Food Corporation in China Based on Consumer Response
}

\author{
Wang Mengdie ${ }^{1,2, *}$ \\ ${ }^{1}$ Wuhan University of Technology, China; ${ }^{2}$ Electric Power of Henan, China
}

\begin{abstract}
This paper introduces the general situation of food security and social responsibility of the enterprise, based on the analysis of Chinese food safety problems. China's Food Enterprise society is facing many difficulties. Based on the consumer response theory, it was pointed out that the problem is mainly caused by the enterprise's two internal and external aspects. The enterprise's internal reason mainly concentrated in three levels: the food business operator's moral level of loss and economic benefits and inefficiency of the enterprise to bear the loss . External factor involves five shortcomings: the lack of government's regulation, incomplete information disclosure system , and imperfect food safety standard system, legal system, and social responsibilities of the standard system . In order to improve the corporate's social responsibility based on Food Safety, this paper put forward some suggestions to strengthen the corporate's social responsibility consciousness and safeguard basic food security of Chinese. Improved internal construction of the enterprise can strengthen the enterprise's responsibility consciousness and enhance the enterprise's the management ability, and the small and medium-sized enterprise training.
\end{abstract}

Keywords: Behavior evaluation, Consumer response theory, Food corporation in China, Social responsibility.

\section{INTRODUCTION}

With the economic and social development, corporate's social responsibility has widely received public's attention. China's food enterprise's society responsibility has become the major issue. Enterprises as important participants in the market economy, are referred to as social and economic cells, directly responsible for the sustained and healthy development of society [1]. Since the introduction of reform, China's food enterprises have been developed rapidly and now have become an important part of the national economy, playing a vital role in the economic and social development [2]. However, in recent years, China's food safety accidents have been frequent. Currently, some food companies have forgotten in the pursuit of their interests their commitment to corporate social responsibility, and they show negligence towards fulfilling their social responsibilities. For instance, Sanlu "toxic milk" Shuanghui "lean" and "fake eggs" and other events, fully exposed that Chinese food corporate , does not fulfill its social responsibilities and obligations [3]. Food companies fulfill their social responsibilities, not only related to the economic efficiency of enterprises, but also related to the interests of consumers and the construction of harmonious society [4].

"People regard food as their prime want." Food safety is related to every consumer. In recent years, a series of food safety incidents have made the food enterprises encounter serious trust issues. The cause of these problems is the lack of corporate social responsibility. The main purpose

*Address correspondence to this author at the Åbo Akademi University, P.O. Box 311, FIN-65101 Vasa, Finland; Tel: +358-6-3247476; Fax:+358-6-3247457; E-mails: jan.saarela@abo.fi; fjalar.finnas@abo.fi of research on the corporate social responsibilities of the food enterprises is fundamentally to find reasons for the lack of corporate social responsibilities of food enterprises, to establish an effective evaluation system of corporate social responsibility and to enhance corporate social responsibility management of the food enterprises. Therefore, the studies on food enterprises social responsibility standards and evaluation have practical significance [5].

Corporate social responsibility standard is an important base to promote enterprise social responsibility management. It was observed that, China has not formed a complete food standard system of corporate society responsibility, therefore, in the absence of an effective government's guidance and business management experience of the premise, it is a huge risk for enterprises and individual to make the standard of enterprise society responsibility, and there are already many drawbacks in the existing food enterprise food enterprise standard system of society responsibility . In this paper, with reference to domestic and foreign food enterprises social responsibility standard system as the foundation, society responsibility standard system of food enterprises reform conception is proposed [6]. The problem of Chinese food enterprises to fulfill the social responsibility is very important both in theoretical research and in practical life [7].

\section{OVERVIEW OF FOOD SAFTY PROBLEM IN CHI- NA}

The laws on food safety in China consist of a set of laws, guided by Food Safety Law, Product Quality Law and Standardization Law, with special regulations on food safety including Food Hygiene Administrative Punishment Measures and Food Hygiene Supervision Procedures as the 
main body, and supplemented by relevant specifications in laws and rules such as Law on Protection of Consumers Rights and Interests, Contagious Law Prevention Law, Criminal Law, etc. These laws are not limited, but characteristic of scattered articles due to the fact section legislation, single law and regulation can only be modified in a narrow scope, with low level of legal force. In addition, some legal specifications are theoretical and abstract therefore, they are difficult to operate. Therefore, in general, global legal regulation system of food life circle from food production to consumption to final treatment has not been established in China yet.

Inherent crossing and overlapping of laws and regulations lead to overlapping arrangement of regulatory agencies and complex main body, affecting supervision . For instance, Product Quality Law specifies industrial, commercial and quality supervision departments are all law enforcement subjects, while current Food Safety Law specifies administrative authorities for industry and commerce, hygiene, quality supervision, agriculture, etc. all undertake food hygiene supervision and management tasks. Indefinite responsibilities are bound to cause repeated law enforcement or vacuum belt of law enforcement, coupled with inconsistency in recognition and understanding of law, driven by departmental interests. Departments will frequently take what they need, compete against each other for rights and interests, evade from responsibly and fight with each other. Hence, the strength of departments cannot be combined, making it difficult for the whole regulatory agency to realize effective integration [8].

Social supervision mechanism of media (including network media and so on), experts, public figures and the public has drawbacks in the field of food safety. Food industry association has not played its due role effectively. Many specific regulations cannot be enforced in practice. Moreover, food industry association has a poor capacity of survival , weak independence, lack of fund and simple organizational structure, affiliated to the local government agency, thus it cannot undertake the supervision responsibilities of food industry. Meanwhile, due to lack of social participation mechanism of food safety volunteers, channels are not available to the public based on food safety.

China's food safety risk management remains at the stage of post-analysis and summary, as the lack of prior risk analysis placing food safety inspection and test in China at the passive status. There is still inadequate risk assessment, risk management and risk pre-warning ability of food safety hazards in China. Moreover, regulators' safety risk is independent of themselves, which is due to lack of supervision of social public.

In the academic circles, corporate social responsibility has no unified definition. Although the definition of corporate social responsibility is different, it is no doubt that enterprises cannot take the profit as the sole purpose. In the pursuit of their own profits, enterprises should take into account the interests of their stakeholders. Corporate stakeholders include consumers, employees, suppliers, investors, government, community, etc. As products buyer, consumers finally decide whether the enterprise can assume economic responsibility. The consumers are undoubtedly the most important stakeholders. To provide consumers the safe food is the most important duty of food enterprises, and it is the primary standard to test whether the food enterprises take social responsibility.

\section{BEHAVIOR EVALUATION METHOD BASED ON CONSUMER RESPONSE}

The primary expression of behavior evaluation method based on consumer response can be expressed as following:

$f^{(\alpha)}(x 0)=\left.\frac{d f(x)}{d x^{\alpha}}\right|_{x=x_{0}}=\lim _{\delta x \rightarrow 0} \frac{\Delta^{\alpha}\left(f(x)-f\left(x_{0}\right)\right)}{\left(x-x_{0}\right)^{\alpha}}$

For $0<a \leq 1$ where

$$
\Delta^{\alpha}\left(f(x)-f\left(x_{0}\right)\right) \cong \Gamma(1+\alpha) \lim _{x \rightarrow \infty} \Delta\left(f(x)-f\left(x_{0}\right)\right)
$$

Local fractional integral of $f(x)$ is defined by Eq. (3).

${ }_{a} I_{b}^{(\alpha)} f(t)=\frac{1}{\Gamma(1+\alpha)} \int_{a}^{b} f(t)(d t)^{\alpha}=\frac{1}{\Gamma(1+\alpha)} \lim _{\Delta t \rightarrow 0} \sum_{j=0}^{j=N-1} f\left(t_{\mathrm{j}}\right)\left(\Delta t_{\mathrm{j}}\right)^{\alpha}$

With $\Delta t=\max \left\{\Delta t_{1}, \Delta t_{2}, \cdots, \Delta t_{j}, \cdots\right\}$ and $\Delta t_{j}=t_{j+1}-t_{j}$, where for $j=1,2, \cdots, N-1,\left[t_{j}, t_{j+1}\right]$ is a partition of the interval $[a, b]$ and $t_{0}=a, t_{N}=b$.

If $f(x)$ is defined on the real line $-\infty<x<\infty$, its fractional function, denoted by $f_{x}^{H, \alpha}(x)$ is defined by

$H_{\alpha}\{f(t)\}=\hat{f}_{H}^{\alpha}(x)=\frac{1}{\Gamma(1+\alpha)} \oint_{R} \frac{f(t)}{(t-x)^{\alpha}}(d t)^{\alpha}$

Where $x$ is real and the integral is treated as a Canchy principal value, that is,

$$
\begin{aligned}
& \frac{1}{\Gamma(1+\alpha)} \oint_{R} \frac{f(t)}{(t-x)^{\alpha}}(d t)^{\alpha} \\
& =\lim _{\varepsilon \rightarrow 0}\left[\frac{1}{\Gamma(1+\alpha)} \int_{-\infty}^{x-\varepsilon} \frac{f(t)}{(t-x)^{\alpha}}(d t)^{\alpha}+\frac{1}{\Gamma(1+\alpha)} \int_{x+\varepsilon}^{\infty} \frac{f(t)}{(t-x)^{\alpha}}(d t)^{\alpha}\right]
\end{aligned}
$$

To obtain the inverse force, writing again Eq. (1) as

$$
\begin{aligned}
& \hat{f}_{H}^{\alpha}(x)=\frac{1}{\Gamma(1+\alpha)} \int_{-\infty}^{\infty} \frac{f(t)}{(t-x)^{\alpha}}(d t)^{\alpha} \\
& =\frac{1}{\Gamma(1+\alpha)} \int_{-\infty}^{\infty} f(t) g(x-t)(d t)^{\alpha}=f(x) * g(x)
\end{aligned}
$$

In the real life, some food companies do not consider how to promote the interests of consumers by their products, and even produce fake food through various means such as by fraud, illegal addition and false advertising in the situation knowing that would damage the consumers' health. It causes damage to the health of consumers directly. These food enterprises bring harm to their consumers, letting alone to reach the realm of altruism. They disobey the basic request of social responsibility. In recent years, all kinds of public food safety events occurred frequently. It fully exposed the serious consequences of the lack of social responsibility in food enterprise. According to the data displayed on the Ministry of Health website, the major food poisoning 
2006-2014 China's major food poisoning events

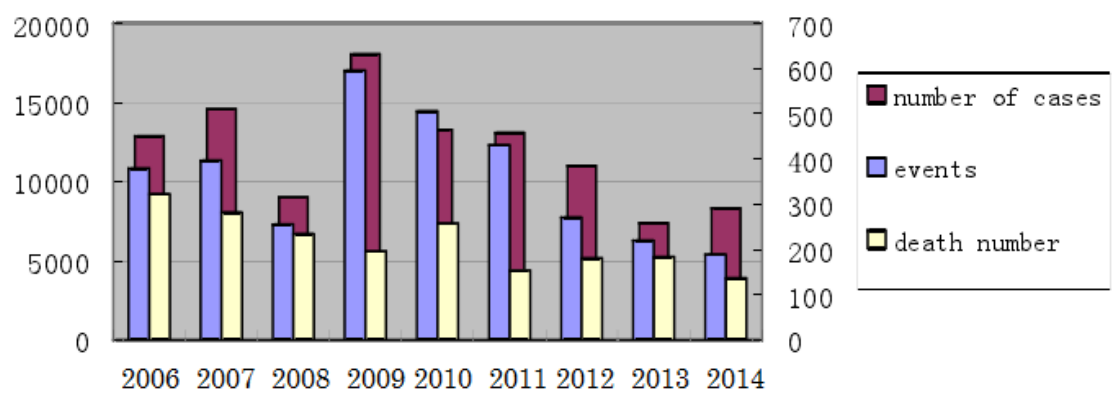

Fig. (1). 2006-2014 China's major food poisoning events.

2010-2011RASFF bulletin of China

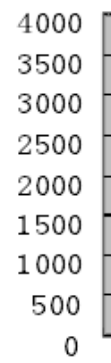

0

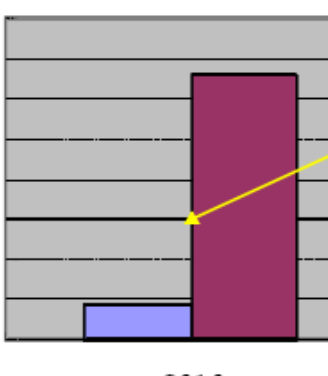

2010

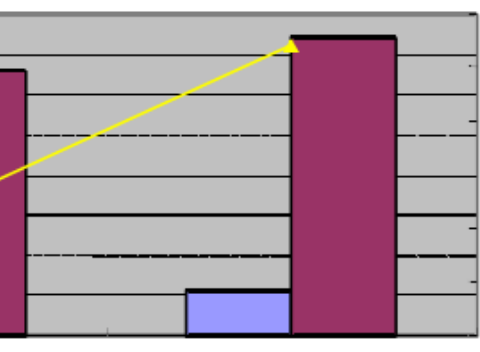

2011
15. $50 \%$

15. $00 \%$

$14.50 \%$

14. $00 \%$

13. $50 \%$

13. $00 \%$

$12.50 \%$

Fig. (2). 2010-2011 RASFF bulletin of China.

RASFF 2011 classification of China

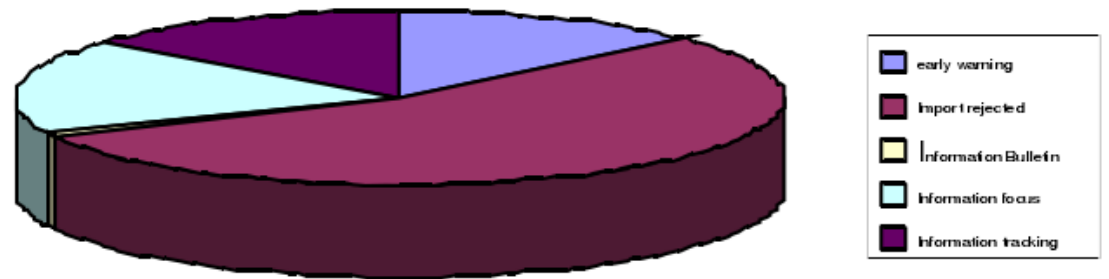

Fig. (3). RASFF 2011 classification of China.

events happened frequently since 2006 to 2014. Although the number of poisoning cases had a downward trend, the deaths did not reduce significantly [9]. The rate of death remained high Fig. (1).

Food safety events happened again and again. They not only damaged consumer's health, but also influenced their food consumption confidence, and some even caused people to arise hitherto unknown anxiety about food. This distrust will gradually make consumers feel panic for the entire food industry, and lead to social instability. The European Union established RASFF to expedite the food safety information since 1979. The food safety administration can take measures according to the information. RASFF announced 3717 bulletins related to food and feed products in 2011, among which 565 bulletins were related to China, which were about $15.2 \%$. The bulletin of China is rising whether in absolute figure or percentage Fig. (2).
According to the announcement, the main problem is about transportation of materials; , heavy metal content and harmful components exceeding the standard. Other causes include materials containing mycotoxin, doping/adulteration, (illegal) transgenic. Because of strict EU food monitoring system, more than $54 \%$ Chinese products were rejected directly Fig. (3).

Pursuing profit is a common demand of enterprise. Food industry is a typical fast consuming industry. The gross margin is low for most food enterprises, except some high-end luxuries. Enterprises mainly rely on the rapid turnover to increase profitability. Food enterprises are associated with labor intensive industry. The labor cost in China increased in the recent years, therefore enterprises have started experiencing an increasing cost pressure. In order to gain shortterm profits, some food enterprises forget the most fundamental social responsibility of providing safe and healthy 
foods. They provide the counterfeit and shoddy products by all means. They only pursue profit maximization.

But the particularity of food determines that the enterprise will pay a heavy price once it is exposed. For example, Sanlu Milk Powder factory announced bankruptcy because of melamine event and was eventually merged with Beijing Three Yuan. Shuanghui Development was reported as the leading enterprise of meat enterprises in China, by the news channel of CCTV in "weekly quality report" in March 15, 2011. Some pigs with "Clenbuterol" used by Jiyuan Shuanghui Food limited Company. Shuanghui brand was ruined greatly after this event. The company's profit fell by $50 \%$ compared with 2010, which ended its successive 10 years positive growth since 2002 .

To ensure the quality of product, the enterprises not only need strict supervision, but also good values. Enterprise values determine the attitudes of employees, their attitudes determine their behaviors. The real social responsibility asks the enterprise to have the conscience, moral demonstration, and selfless giving. If there are no outstanding values of strong support coming from management, if the enterprises do not pursue good morality such as persevered sincerity, they will concentrate on details but forget the main purpose about social responsibility. While performing corporate social responsibility, enterprises must return to their major purpose and the essence of the spirit, which involves absolutely guaranteeing safety of consumers. Moreover, it is also an essential requirement to realize the consumer's value. In the short term, inputs to social responsibility will increase the cost of an enterprise, and reduce the profit. But in the long run, the two are mutually promoted to establish a benign relationship. Good corporate social image will win the stakeholders' support. This will lead to the greater development of enterprises and the profit will also be billowing.

As the food industry has a long chain of industries, only the establishment of food safety traceability system cannot solve the problem because the responsibility is difficult to define. And the food safety traceability system serves as a protection to final link of the industrial chain business. Food accidents tend to occur on specific, individual batches of product. If the production enterprises are inspected indiscriminately, the loss of enterprises will be increase. In the establishment of food safety traceability system, the problem can be rapidly found, and the enterprise can disclose the truth in time. In the United States, if something is wrong with the quality of a beef or steak, it will soon be traced back to the product obtained from the cow and two to three matrix just with a DNA scanner. This reduces the loss of large scale recalling.

Therefore the food enterprises at the end of the industrial chain should increase the input actively, and make every possible effort to promote food safety traceability system. Under effective food traceability mechanism, enterprises from upstream to downstream assume their social responsibility respectively and work together to create a safe food chain. Enterprises should respond quickly after food safety accident, formulate the disposal scheme, and establish handling mechanism and compensation system. Enterprises should implement recall system on the defective products produced while designing, manufacturing selling and by other links. Recall system is the last effort for food production enterprises to save the enterprise's reputation, eliminate consumer panic and assume social responsibility.

In developed countries such as Europe and America, the whole-process supervision is the common characteristic of food regulatory system. In the United States, there are threestage regulatory agencies: federal, state and territory. These agencies employ epidemiologists, microbiologists and food scientific research experts to visit the food processing plants, and farms directly. They undertake all-around supervision from raw materials acquisition, production, circulation, to sales and customer service. A stereo supervisory network is used to report all the country. The European Union in the "Food Safety White Paper" proposed a radical reform in Jan 12, 2000 in order to control the whole process "from farm to table", including common animal breeding, animal health and health care, contaminants and residues of pesticides, new food, additives, flavor, packaging, radiation, feed production, farmers, food producers responsibility and a variety of agricultural control measures.

China's current food supervision system follows vertical distribution. In the county level, individuals, money, and material are insufficient. There are only one or two experts in some county supervision branches. Supervision strength is very weak in the basic level. Due to the fact that front-line supervision staff is very few it is difficult to achieve normal regulation starting from the source. They can only take remedial measures after the food incident. To improve China's food monitoring system, the multiple segmented supervision system needs to be amended. It is important to greatly strengthen the basic supervision power, and conduct a comprehensive survey on current food production, and consumption areas.

\section{CONCLUSION}

All levels of food safety supervision departments should reinforce punishment against the case of illegal food under the guidance of "food safety law" and its implementation rules. The cost of crime involving food must be enhanced. Under the current "food safety law", government should increase the punishment level irrespective of personal damages compensation or punitive compensation. In addition, we can draw lessons from foreign experience, for example, market prohibition system. The illegal enterprises are not allowed to be a part of food industry in any way in the next several years.

\section{CONFLICT OF INTEREST}

The author confirms that this article content has no conflict of interest.

\section{ACKNOWLEDGEMENTS}

This work is supported by the Key Project of Guangxi Social Sciences, China (No. gxsk201424), the Education Science fund of the Education Department of Guangxi, China (No. 2014JGA268), and Guangxi Office for Education Sciences Planning, China (No. 2013C108). 


\section{REFERENCES}

[1] F. O. H. Stephan, "Corporate social responsibility: Doing well by doing good," Business Horizons, vol. 2, pp. 247-254, 2007.

[2] F. Yong-xiang, "Deeply overviewing the codex alimentarius and the proposals on constructing national food safety standards system in China”, Chinese Journal of Food Hygiene, vol. 3, pp. 104-109, 2010.

[3] M. Hartmann, "Corporate social responsibility in the food sector," European Review of Agricultural Economics, vol. 2, pp. 297-324, 2011.

[4] O. Christopher, "The attitudes of united states and south african managers to corporate social responsibility," Journal of Business Ethics, vol. 3, pp. 89-96, 1987.
[5] S.S. Bhattacharya, "Does doing well always lead to doing better? consumer reactions to corporate social responsibility," Journal of Marketing Research, vol. 2, pp. 225-243, 2011.

[6] S. Jamie, H.R. Paul, and M. Diane, "Corporate social responsibility in the $21^{\text {st }}$ century: A view from the world's most successful firms," Journal of Business Ethics, vol. 2, pp. 175-187, 2003.

[7] W. Xiao-li, "To study simply on social responsibility of food corporation based on the food safety perspective," Value Engineering, vol. 2, pp. 554-560, 2009.

[8] Z. Guang-hui, "Reflections on improving the traceability supervision system of livestock meat production in China," Chinese Journal of Food Hygiene, vol. 6, pp. 13-21, 2011.

[9] Z. Zu-cheng, Business Ethics, Tsinghua University Press: Beijing, 2008.

Received: June 10, 2015

Revised: July 29, 2015

Accepted: August 15, 2015

(C) Wang Mengdie; Licensee Bentham Open.

This is an open access article licensed under the terms of the (https://creativecommons.org/licenses/by/4.0/legalcode), which permits unrestricted, noncommercial use, distribution and reproduction in any medium, provided the work is properly cited. 